\title{
Coulisses
}

Revue de théâtre

4 | Été 1991

Varia

\section{En parlant avec le metteur en scène}

\section{Gisèle Holtzer}

\section{OpenEdition}

Journals

Édition électronique

URL : http://journals.openedition.org/coulisses/1683

DOI : $10.4000 /$ coulisses. 1683

ISSN : 2546-9460

\section{Éditeur}

Presses universitaires de Franche-Comté

\section{Édition imprimée}

Date de publication : 1 juin 1991

Pagination : 31-33

ISSN : 1150-594X

\section{Référence électronique}

Gisèle Holtzer, «En parlant avec le metteur en scène », Coulisses [En ligne], 4 | Été 1991, mis en ligne le 04 juillet 2017, consulté le 22 octobre 2019. URL : http://journals.openedition.org/coulisses/1683 ;

DOI : 10.4000/coulisses. 1683

Ce document a été généré automatiquement le 22 octobre 2019

Coulisses 


\section{En parlant avec le metteur en scène}

\section{Gisèle Holtzer}

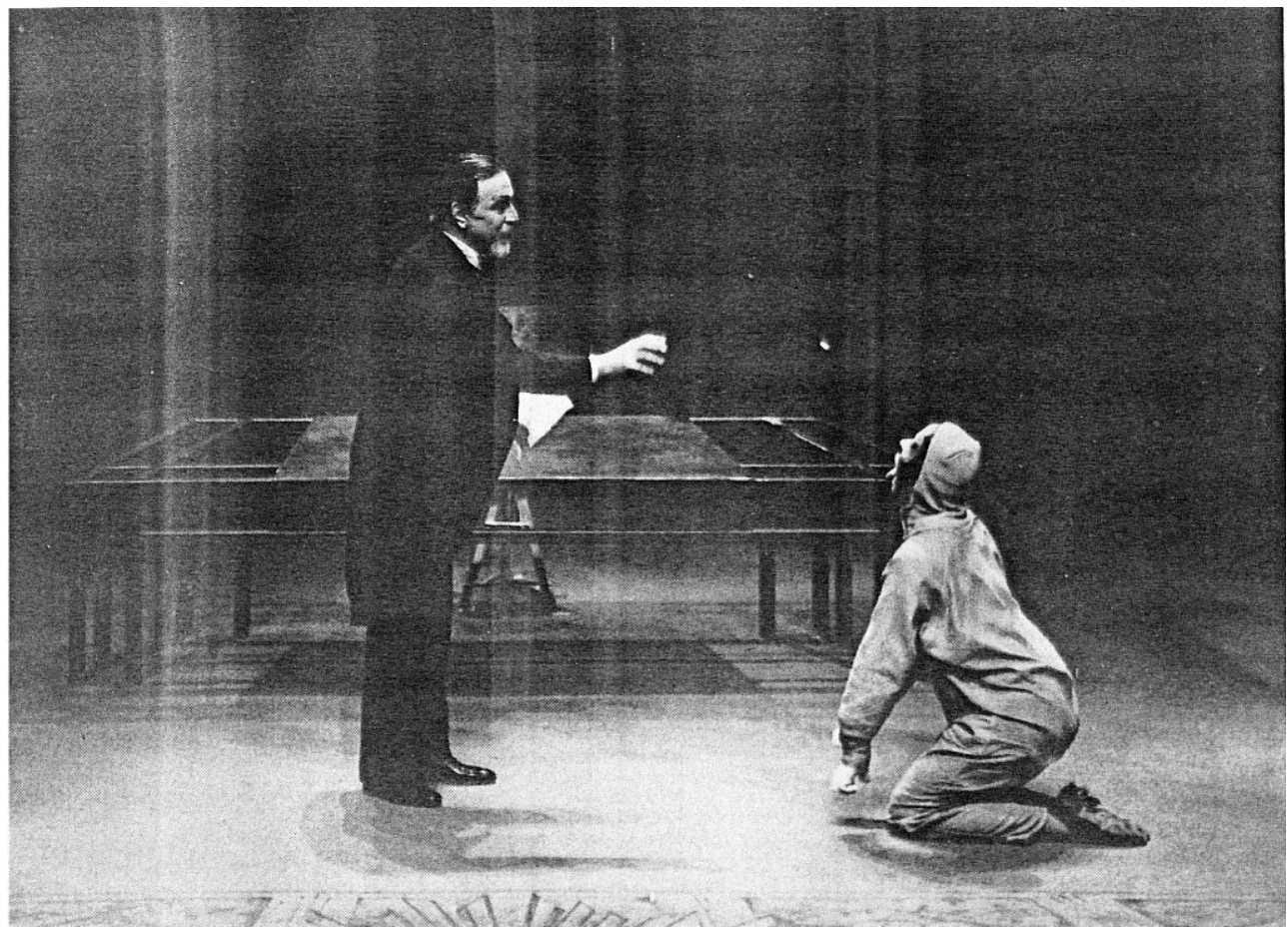

Le professeur et Boule.

Photo J. Daubas.

Pour Patrick Melior, mettre en scène Couur de chien est l'aboutissement de lectures en écho, réseau de références culturelles unissant hors du temps Cervantes, Hoffmann et Boulgakov. Le premier maillon est un texte de Cervantes Colloque des chiens, dialogue à portée philosophique où deux chiens conversent sur la réalité du monde. E.T.A. Hoffmann est le trait d'union entre Cervantes et Boulgakov : il écrivit en effet une suite à Colloque des chiens et l'écrivain russe fit partie d'un club littéraire Les Frères Sérapion, ainsi intitulé en hommage à Hoffmann. Selon P. Melior, qui a mis en scène Princesse Brambilla en 1980, il existe une grande communauté de pensée entre les deux auteurs: 
« Il y a chez Hoffmann une vision poétique à la fois désespérée et pleine d'humour que l'on retrouve chez Boulgakov. Certains récits prémonitoires, fantastiques, un peu inquiétants de Boulgakov rappellent étrangement l'univers de Hoffmann. »

Dès la première phrase, Cour de chien se situe dans le fantastique : un chien des rues nous parle. Cette dimension surnaturelle et très théâtrale, la modernité de l'écriture sont à l'origine du désir de mettre en scène le récit de Boulgakov. Mais c'est aussi le contenu philosophique de l'œuvre qui a motivé l'activité d'adaptation :

Le souffle épique, poétique, la passion des grands auteurs me touchent infiniment plus que certains textes que l'on dit modernes.

J'ai besoin que ce qui est dit s'inscrive dans une perspective qui nous dépasse. Je ne pense pas que le théâtre soit l'image inversée de la réalité, le miroir du monde et je n'ai pas envie de mettre sur scène la quotidienneté dans ce qu'elle peut avoir de trivial.

3 Le metteur en scène a avant tout voulu être au service de l'œuvre, parler de Boulgakov en essayant de révéler par le théâtre ce qui reste caché, souterrain :

Les personnes qui connaissent Boulgakov ont trouvé que j'ai été fidèle à l'esprit de l'auteur et c'est vraiment la première chose que je voulais défendre. L'auteur dramatique, pour moi, est un poète, quelqu'un qui est habité par un univers et moi, en tant que metteur en scène, j'essaie de révéler ce que je ressens comme profond.

P. Melior a fait l'adaptation de Cœur de chien à partir de deux traductions, l'une réalisée par un français, l'autre par un russe. Les deux versions diffèrent sensiblement :

La traduction du français coule beaucoup mieux, paraît mieux écrite, plus élégante d'un certain point de vue. On voit par là combien l'écriture traduit, trahit une culture. Le traducteur russe est lui plus brutal ; il emploie des mots un peu décalés et j'aime beaucoup ça. C'est une traduction qui a peut-être plus de qualité pour ce que je voulais en faire. Cela a redonné de la violence au texte. De façon générale, je vais dans le sens d'une certaine violence; ce qui est lisse, bien fait m'intéresse moins que ce qui est matière brute.

5 Le chien Boule, avec son intelligence pratique, son humour, son humanité, est immédiatement sympathique au lecteur comme au spectateur. Après sa deuxième naissance - sa transformation en homme - il devient un être sournois et lâche, un délateur (il dénonce le professeur Preobrajenski en l'accusant de tenir des « discours contre-révolutionnaires »).

On peut trouver Boule antipathique et dire que le bon chien se transforme en mauvais homme. En fait, c'est une victime ; plus j'ai travaillé sur le texte, la mise en scène, plus j'ai vu en lui une victime - dans un premier temps la métaphore du peuple russe - quelqu'un dont on a pitié. Le diable, qui est un thème majeur chez Boulgakov, ce n'est pas Boule mais le professeur. Celui-ci est par ailleurs un homme de culture qui a des côtés attirants; il défend certaines valeurs que l'on peut partager. Ce qui me passionne dans Boulgakov, c'est l'absence de schématisme. La fable est simple mais il faut la lire de façon moins simple. Il y a dans le texte original des mots, des notations suffisamment contradictoires pour laisser place à une lecture approfondie aux significations plus denses.

6 Les récents événements de l'Est ne sont pas sans influence sur la réception de Cœur de chien , récit porteur d'une dimension satirique par rapport au régime. Le spectateur a une perception « actualisée » de ce qui est dit et montré, perspective qui agace un peu le metteur en scène :

Il y a sans doute une ambiguïté entre mes intentions et ce qu'a pu recevoir le public. Mes intentions sont anciennes - ma première adaptation de Cour de chien date de cinq, six ans - plus universelles, plus philosophiques aussi. Ce qui a été lu l'a été au 
regard de l'actualité, de façon immédiate. Il aurait fallu que je le fasse il y a cinq ans, pour éviter la rencontre avec l'Histoire!

7 La musique de Cour de chien est signée Chostakovitch, créateur dont le destin rappelle celui de Boulgakov. Texte et musique sont unis par une étroite correspondance : les chants juifs, les parodies musicales sont « l'âme de ce qui est dit ». La musique a ici sa fonction essentielle qui est de participer à la signification profonde de l'œuvre.

Ceux qui n'ont pas assisté à la représentation de Cour de chien peuvent (re)lire le récit de Boulgakov écrit en 1925 et dont la première publication en URSS date... de 1987.

У·-у-у-у-у-гу-гуг-гуу! 0, гллшьте на меня, я по. гибаю. Вьюга в подворотне ревет мие отходную, I л вою с пеї. Пропал я, пропал. Негодлӥ в грязном колпаке - повар столової пормального пнтания служапих Центрального Совета Народного Хозяйства - плеспул киплтком п обварпл жне левый бок. Какал гадпна, а еще пролетарпї. Господш, Боже мой - как больпо! До костей проето кппяточком. Я теперь вог, вою, да разве воем поможешь.

Чем я ему помешал? Неужелп л обожру Совет Народного Хозлійства, если в помойке пороюсь? Жіадная тварь! Вы гляньте когда-нибудь на его рожу: ведь оп поперек себя шире. Вор с медної Мордой. Ах, люді, людн. В полдень угостпл меня колпак киплтком, а сейчас стемнело, часа четыре прнблпзительпо пополудип, судя по тому, как луком пахпет пз пожарной Пречнстенской коханды.

Le début du récit de Boulgakov. 
*Whouu, whouuu, whouhouhouhouuuuuu !"

* Regardez-moi, je meurs. Jusque sous le porche, la tourmente vient me hurler sa prière des agonisants, et je hurle avec elle. C'est fini, je suis fini. Un bon à rien coiffé d'une toque crasseuse - le cuisinier de la cantine des employés du Conseil central de l'Économie nationale - m'a ébouil. lanté le flanc gauche. L'ordure! Et ça s'appelle un prolétaire. Mon Dieu, que j'ai mal! Il m'a brûlé jusqu'à l'os. Et maintenant, je hurle, je hurle, mais ça m'avance à quoi ?

"Qu'est-ce que je lui avais fait ? Je n'allais tout de même pas ruiner le Conseil de l'Économie nationale en remuant quelques ordures. Rapiat! Vous avez vu sa gueule, à cet incorruptible ? Il est plus large que haut. Ah, les hommes, les hommes... A midi, j'ai eu droit à ma ration d'eau bouillante ; maintenant, il fait presque nuit, il doit être 4 heures de l'après-midi, à en juger par l'odeur d'oignon qui vient de la caserne de pompiers de la Pretchistienka. 